\title{
Benign Laryngeal Neoplasm
}

National Cancer Institute

\section{Source}

National Cancer Institute. Benign Laryngeal Neoplasm. NCI Thesaurus. Code C3601.

A non-metastasizing neoplasm that arises from the larynx. Representative examples

include squamous papilloma and hemangioma. 